\title{
Educação profissional, dualidade estrutural e neoprodutivismo
}

\author{
Elisabete Ferreira Borges \\ José Carlos Souza Araújo \\ Universidade de Uberaba (Brasil)
}

\section{Resumo}

Reconstruir a trajetória a respeito da dualidade entre o ensino profissional e o ensino médio no Brasil, no decorrer do período republicano, através do referencial teórico-neoprodutivista, constitui-se o objetivo principal deste artigo. Tal referencial tem, como princípio, a dialética, e inclui, quanto à metódica, dois movimentos interligados: a pesquisa bibliográfica e a documental. A dualidade estrutural do sistema de ensino continua configurando trajetórias e finalidades com padrões diferenciados de ensino para classes sociais distintas. Nesse sentido, há o predomínio do neoprodutivismo como referencial teórico da organização atual do sistema de ensino. $\bigcirc$ desafio que se coloca, atualmente, é o de reverter essa situação buscando o resgate da dignidade de milhares de seres humanos condenados à marginalidade das conquistas que a humanidade conseguiu através do capital e do desenvolvimento científico e tecnológico.

Palavras-chave: Educação média. Educação profissional. Dualidade estrutural. Neoprodutivismo.

\section{Vocational education, structural duality and neoproductivism}

\section{Abstract}

The main objective of this article is to reconstruct the trajectory regarding the duality between vocational and high school education in Brazil during the Republican period, through the neoproductivist referential. Such a reference has, as a principle, the dialectic and includes, in terms of the method, two interlinked movements: bibliographical and documentary research. The structural duality of the education system continues to shape trajectories and purposes with differentiated teaching patterns for distinct social classes. In this sense, there is the predominance of neoproductivism as a theoretical reference of the current organization of the education system. The challenge now is to reverse this situation by seeking the redemption of the dignity of thousands of human beings condemned to the marginality of the achievements that humanity has achieved through capital and scientific and technological development.

Keywords: High school education. Vocational education. Structural duality. Neoproductivism. 
Educação profissional, dualidade estrutural e neoprodutivismo

\section{Educación profesional, dualidad estructural y neoproductivismo}

\section{Resumen}

Reconstruir la trayectoria con respecto de la dualidad entre la enseñanza profesional y la enseñanza media en Brasil, a lo largo del período republicano, a través del referencial teórico neoproductivista, constituye el objetivo principal de ese artículo. Tal referencial tiene como principio la dialéctica, e incluye, en cuanto a la metódica, dos movimientos interconectados: la investigación bibliográfica y la documental. La dualidad estructural del sistema de enseñanza continúa configurando trayectorias y finalidades con patrones diferenciados de enseñanza para clases sociales distintas. En ese sentido, hay el predominio del neoproductivismo como referencial teórico de la organización actual del sistema de enseñanza. El desafío que se plantea actualmente es el de revertir esa situación buscando el rescate de la dignidad de miles de seres humanos condenados a la marginalidad de las conquistas que la humanidad ha logrado a través del capital y del desarrollo científico y tecnológico.

Palabras clave: Educación media. Educación profesional. Dualidad estructural. Neoproductivismo.

\section{Introdução}

A título de problematização, a compreensão da proposta de formação técnica e profissional, definida a partir da Lei $n^{\circ} 13.415$, de 16 de fevereiro de 2017, que instituiu a Política de Fomento à Implementação de Escolas de Ensino Médio em Tempo Integral, demanda que se analise como a educação profissional se desenvolveu no Brasil. Os modelos pedagógicos constituem-se a partir de mudanças que ocorrem no mundo do trabalho e das relações sociais, visto que as classes responsáveis pelas funções essenciais no mundo da produção precisam formar adequadamente seus recursos humanos. Essa compreensão só é possível com base nas relações estabelecidas entre trabalho e educação nas diferentes etapas do desenvolvimento das forças produtivas.

Para analisar as relações entre educação e trabalho, num primeiro momento, será desenvolvida uma breve reconstrução histórica do ensino profissional no Brasil, bem como sua relação com o sistema produtivo em cada época abordada. No tocante aos meados do século XX, será enfocada, sucintamente, a Teoria do Capital Humano que coincide com a ênfase dada ao caráter economicista da educação que começa a ser engendrada e, depois, 
oficialmente estabelecida pelo governo militar uma proposta tecnicista para o sistema de ensino no Brasil.

Num segundo momento, serão analisadas as mudanças ocorridas na educação brasileira, a partir dos anos de 1980 e 1990, com a substituição da Teoria do Capital Humano pelo conceito de empregabilidade. A empregabilidade mantém a mesma ótica economicista, produtivista e tecnicista enquanto referencial teórico, orientador da organização do sistema de ensino, mas retira a dimensão centrada no desenvolvimento social, presente na Teoria do Capital Humano, pois passa a enfatizar os interesses privados e o modelo de competência que cada indivíduo deve adquirir para atingir uma melhor posição no mercado de trabalho.

Ou seja, desde o final do século XX, a Teoria do Capital Humano se expressa como neoprodutivismo, calcado em três variantes: neoescolanovismo, neoconstrutivismo e neotecnicismo, o que decorre das transformações materiais ocorridas a partir da "[...] passagem do fordismo ao toyotismo, determinando uma orientação educativa que se expressa na 'pedagogia da exclusão'" (SAVIANI, 2013, p. 441).

Nesse contexto, na segunda década do século XXI, por meio da promulgação da Lei n 13.415, de 16 de fevereiro de 2017, que instituiu a Política de Fomento à Implementação de Escolas de Ensino Médio em Tempo Integral, há uma reformulação na legislação brasileira: a formação técnica e profissional passa a ser um segmento do Ensino Médio. Nesse longo caminho de separação e integração, sempre houve a manutenção da dualidade estrutural entre o ensino médio acadêmico e o ensino profissional como reflexo das diferentes condições socioeconômicas das classes sociais no Brasil.

A Lei no 13.415, de 16 de fevereiro de 2017, reitera a estrutura educacional dos anos de 1940, ao estabelecer no artigo $4^{\circ}$ que houvesse oferta das "[...] seguintes áreas de conhecimento: I - linguagens e suas tecnologias; II matemática e suas tecnologias; III - ciências da natureza e suas tecnologias; IV - ciências humanas e sociais aplicadas; $V$ - formação técnica e profissional".

Assim, como ocorreu com a Reforma Capanema, na década de 1940, que separava o ensino médio em clássico e científico para preparar para o ingresso no ensino superior em suas principais áreas de conhecimento, e as modalidades técnicas para aqueles que necessitavam ingressar logo no mercado de trabalho, a nova lei propõe uma formação diferenciada para os 
Educação profissional, dualidade estrutural e neoprodutivismo

alunos que podem preparar-se para o ensino superior, com opções pelas ciências e humanidades, e pela opção técnica e profissional para os que precisam entrar mais cedo para o mundo do trabalho e suas adversidades.

\section{Historiando o ensino profissional no Brasil}

No Brasil, a educação, desde a época da Colônia até a Primeira República, não tinha grande significado para a maioria da população. Nesse período, a monocultura exigia o mínimo de qualificação e de diversificação da força de trabalho, enquanto a estrutura social, pouco diferenciada, praticamente não precisava de educação para manter-se. As escassas mudanças, sofridas pela sociedade até o final do modelo agrário-exportador (RIBEIRO, 19781, não impunham maiores demandas à educação.

Todavia, o tipo de ensino secundário organizado pelos jesuítas, ainda no período colonial, ao contrário do ensino que era destinado aos negros e aos índios, propiciou o aparecimento de alguns valores que, até hoje, marcam a educação brasileira, tais como: a importância dada à atividade intelectual, o menosprezo pela atividade manual e o significado social do diploma de curso superior.

Segundo Saviani (2013), esse é o primeiro período da educação brasileira, caracterizado, por ele, de monopólio da vertente religiosa da pedagogia tradicional, subdividida em duas fases: a primeira, denominada de pedagogia brasílica ou, o período heroico (1549-1599), e a segunda fase caracterizada pela institucionalização da pedagogia jesuítica através da Ratio Studiorum (1599-1759).

Cem anos antes do Decreto-Lei $n^{0} 7.566$, de 23 de setembro de 1909, que estabeleceu na quase totalidade dos estados escolas de aprendizes artífices, pelo Decreto de 23 de março de 1809 dava providências em relação ao Colégio das Fábricas no Rio de Janeiro:

Attendendo a acharem-se trabalhando e aprendendo á custa da minha Real Fazenda na Casa denominada Collegio das Fabricas [...] varios artifices, manufactureiros, aprendizes vindos de Portugal, e isso em virtude das providencias que fui servido dar para a sua subsistencía em utilidade do comrnercío e indústria [... ] e tendo consideração ao arranjamento e economia, [...] hei por bem, que pelo 
meu Real Erário, na fórma até agora praticada [...] se continuem a pagar as folhas dos jornaleiros ali empregados [...]. Palacio do Rio de Janeiro 23 de março de 1809. Com a rubrica do Príncipe Regente Nosso Senhor (BRASIL, 1809).

Em 1812, D. João, Príncipe Regente, em sua Carta Régia de vinte e cinco de junho de 1812, orienta a criação de um curso de Agricultura na Bahia. A Imperial Escola da Bahia, criada em vinte e três de junho de 1875, situava-se no Engenho São Bento, e foi organizada para ofertar dois níveis para o ensino profissional agrícola: o elementar destinado a habilitar regentes agrícolas, operários e florestais, e o superior determinado a formar engenheiros agrônomos e veterinários (FERREIRA, 2002).

Ainda, no período imperial, o Conselheiro Rui Barbosa, em 1882, apresenta substitutivo ao projeto de reforma da instrução, elaborado por Souza Dantas, Ministro do Império, e propõe: a) aulas de desenho industrial em cada paróquia da capital; b) escolas de arte industrial nas províncias; c) Escola Normal Nacional de Arte Aplicada, na Corte; e d) criação, no Imperial Colégio de Pedro II, de seis cursos profissionais: finanças e comércio, máquinas, industrial, relojoaria e instrumentos de precisão (MACHADO, 1989).

Ainda nesse período, um precário sistema de educação formal foi se estruturando e cristalizando o seu caráter discriminatório. Essa estrutura ocorreu com o surgimento dos sistemas provinciais, justapostos ao do governo central. As províncias cuidaram da organização do ensino primário seguido pela educação vocacional, de prendas para a mulher, e de ofícios para o homem. $\bigcirc$ governo central cuidava dos cursos preparatórios, da educação secundária acadêmica e do ensino superior, destinado à formação da elite. Os dois tipos de sistema - provincial e central - eram independentes, um não dando passagem ao outro.

A República não trouxe alterações significativas para a estrutura social do Brasil. $\bigcirc$ novo regime político acabou por referendar, na primeira Constituição Republicana, de vinte e quatro de fevereiro de 1891, a mesma organização descentralizada de ensino herdada do período imperial. Levando-se em consideração as diferenças entre o que se estabelecia na lei e o que determinava a realidade concreta, Romanelli (1995) apresenta o real quadro que se estabeleceu naquele período: 
Educação profissional, dualidade estrutural e neoprodutivismo

[...] a União cabia criar e controlar a instrução superior em toda a Nação, bem como criar e controlar o ensino secundário acadêmico e a instrução em todos os níveis no Distrito Federal, e aos Estados cabia criar e controlar o ensino primário e o ensino profissional, que na época, compreendia principalmente as escolas normais, para moças, e as escolas técnicas para rapazes (ROMANELLI, 1995, p. 4).

resultado foi que decorreram ações, na área educacional, completamente independentes, e mesmo díspares, entre União e Estados, gerando a impossibilidade de se construir, nos tempos iniciais da República, um sistema educacional único.

Foi no início do Brasil República, porém, de modo incipiente, que começaram a surgir iniciativas concretas voltadas à formação de profissionais para a agricultura. Os reflexos da abolição da escravidão se traduziam, efetivamente, em sinais de escassez de mão de obra no campo e, consequentemente, de gêneros alimentícios para o consumo interno, em especial, na produção do café.

Uma readequação às novas relações de produção capitalista foi necessária, além da introdução de técnicas de produção relacionadas ao plantio, tratos culturais, colheita, beneficiamento, classificação e comercialização do café. Para enfrentar os problemas que se instalaram na agricultura brasileira, intensificaram-se os investimentos no preparo de mão de obra, partindo do pressuposto de que o uso de tecnologia se constituía no principal fator para o aumento da produtividade.

Outros recursos, tais como a organização de empresas de colonização com base em mão de obra imigrante e a utilização de técnicas de produção agrícola - em especial aquelas relativas ao café, - diretamente ligadas à própria organização do ensino agrícola - foram utilizados pelos administradores públicos da época.

Até 1906, o ensino agrícola estava diretamente ligado à presidência da República. A partir desse ano, a Lei n 1.606, de 29 de dezembro de 1906, homologada pelo Presidente Nilo Peçanha, conhecida como Lei Peçanha, e regulamentada pelo Decreto-Lei $n^{\circ} 7.566$, de 23 de setembro de 1909, criou, em quase todos os estados, escolas de aprendizes artífices, o que marcou o início da atuação direta do governo federal na área da formação profissional. Assim expressa o seu texto original: 
presidente da República dos Estados Unidos do Brasil, em execução da lei n 1.606 de 29 de dezembro de 1906, considerando que o aumento constante da população das cidades exige que se facilite às classes proletárias os meios de vencer as dificuldades sempre crescentes da luta pela existência; que para isso se torna necessário, não só habilitar os filhos dos desfavorecido da fortuna com o indispensável preparo technico e intelectual, como fazê-los adquirir hábitos de trabalho profícuo, que os afastará da ociosidade ignorante, escola do vício e do crime; que é um dos primeiros deveres do governo da República formar cidadãos úteis a nação (FERREIRA, 2002, p. 20).

Tal decreto representou uma medida mais no sentido de combater os problemas sociais decorrentes da urbanização crescente e menos para a formação de mão de obra qualificada, considerando que o desenvolvimento industrial, naquele momento, era incipiente. Mesmo assim, a formação profissional, como responsabilidade do Estado, inicia-se aí, em 1909, com a criação de dezenove escolas de artes e ofícios nas diferentes unidades da federação. As escolas, então criadas, não se articulavam com os demais graus de ensino, e destinavam-se à classe operária, enquanto o ensino propedêutico e intelectual era destinado à classe dominante.

O Decreto $n^{\circ} 12.893$, de 28 de fevereiro de 1918, cria os patronatos agrícolas com o objetivo de atender, preferencialmente, menores desfavorecidos da sorte, aos quais seriam dados os cursos primário e profissional. Esses patronatos agrícolas surgiram vinculados ao regime de colonato que previa a posse de um lote de terra, em determinado núcleo colonial, livre de despesas, e mais a quantia de duzentos mil réis para os alunos que concluíssem o curso profissional com aproveitamento. Desse modo, o ensino agrícola cumpria a função de manter o homem no campo, oferecer mão de obra especializada e aumentar a produção de alimentos (FERREIRA, 2002).

Essa situação permanece até a Primeira Guerra Mundial. Na economia, continuava o predomínio do modelo agrário-exportador (CUNHA, 1977). Nesse modelo, a relação entre educação e trabalho é pequena. A estrutura econômica do país não exigia que a população, de modo geral, fosse socializada via escola. Os valores tradicionais eram adequados à vida rural e às relações estabelecidas entre proprietários de terra e trabalhadores.

Os anos de 1920 foram bastante agitados no país. Com a crise do setor cafeeiro e as dificuldades impostas pela conjuntura mundial de importar 
Educação profissional, dualidade estrutural e neoprodutivismo

produtos manufaturados, o país precisava suprir ele próprio suas necessidades básicas, criando, para isso, o seu setor industrial. Esse processo, contudo, não ocorreu de forma gradativa e contínua; pelo contrário, foi se processando a reboque da política do café.

Enquanto o setor cafeeiro era tratado com privilégios, a indústria encontrava dificuldades de créditos e restrições na importação de equipamentos. Um descontentamento geral surge com essa política que se agrava com a instabilidade social, decorrente do crescimento de grupos como a pequena burguesia e o proletariado, culminando com a eclosão do movimento de 1930.

Nos anos de 1930, ocorre outra fase de organização administrativa e de regulamentação do ensino agrícola, que foi desmembrado do Departamento Nacional de Produção Vegetal, do Ministério da Agricultura, por meio do Decreto-Lei n 982, de 23 de dezembro de 1938. Esse Decreto cria a Superintendência do Ensino Agrícola (SEA), cujo Regimento foi aprovado pelo Decreto $n^{\circ}$ 16.826, de 13 de outubro de 1944, com a denominação alterada para Superintendência do Ensino Agrícola e Veterinário (SEAV-MA). Simultaneamente, o ensino secundário permanecia com seu caráter propedêutico.

Cury (2002), ao se referir ao ensino médio, recorre ao antológico Manifesto dos Pioneiros da Educação Nova, ocorrido, em 1932, que previa um Plano de Reconstrução Educacional. Assim, afirmava:

[...] o ponto nevrálgico da questão educacional era a então chamada escola secundária. Assim, uma reforma integral da organização e dos métodos de toda a educação nacional na qual a escola secundária unificada para se evitar o divórcio entre os trabalhadores manuais e intelectuais, terá uma sólida base comum de cultura geral (três anos), para posterior bifurcação (dos 15 aos 18), em seção de preponderância intelectual (com os três ciclos de humanidades modernas; ciências físicas e matemáticas; e ciências químicas e biológicas), e em seção de preferência manual, ramificada por sua vez em ciclos, escolas ou cursos destinados à preparação às atividades profissionais, decorrentes da extração das matérias-primas (indústrias e profissionais) e da distribuição dos produtos elaborados (transportes, comunicações e comércio) (CURY, 2002, p. 15). 
Cury (2002, p. 15-16) prossegue afirmando que, após 70 anos do referido Manifesto, "[...] muita coisa se modificou, outras nem tanto. As leis avançaram e muito! A economia se modificou e quanto! Mas não o nosso acerto de contas com a modernidade econômica e democracia social e política para todos". Naquela época, os chamados Pioneiros da Escola Nova já haviam identificado a difícil questão da dualidade do sistema de ensino e apresentaram uma proposta para a sua superação. Dessa forma, percebe-se a complexidade que envolve essa situação e que ultrapassa os limites da escola.

No período que vai de 1930 a 1945, o Estado viabiliza o processo de industrialização e esboça a planificação da economia. Com a posse do presidente Getúlio Vargas, o Estado toma consciência da importância estratégica do sistema educacional para assegurar e consolidar as mudanças estruturais ocorridas, passando a regulamentar a organização e o funcionamento do ensino, submetendo-o ao seu controle direto. Na gestão de Francisco Campos, no Ministério da Educação e Saúde Pública, foram aprovados projetos de reforma do ensino secundário e comercial. Todavia, persistia a ideia de que o ensino profissional não se igualava ao ensino acadêmico.

A Constituição Federal, de 10 de novembro de 1937, ao legislar sobre o ensino profissional, o faz de modo a reavivar o preconceito contra o trabalho manual, destinando-o, explicitamente, às classes menos favorecidas:

O ensino pré-vocacional destinado às classes menos favorecidas é, em matéria de educação, o primeiro dever do Estado. Cumpre-thes dar execução a esse dever, fundando institutos de ensino profissional e subsidiando os de iniciativa dos Estados, dos Municípios e dos indivíduos ou associações particulares e profissionais. É dever das indústrias e dos sindicatos econômicos criar, na esfera de sua especificidade, escolas de aprendizes, destinadas aos filhos de seus operários ou de seus associados. A lei regulará o cumprimento desse dever e os poderes que caberão ao Estado sobre essas escolas, bem como os auxílios, facilidades e subsídios a thes serem concedidos pelo poder público (BRASIL, 1937).

Do ponto de vista político, no entanto, a questão era tensionada por concepções diferentes, porém expressas, por um lado, pelo Ministro da Educação, Gustavo Capanema, e por outro, pelo Ministro do Trabalho, Valdemar Falcão. O primeiro defendendo que o ensino profissional deveria submeter-se ao controle do Estado, enquanto o segundo defendia os cursos 
Educação profissional, dualidade estrutural e neoprodutivismo

profissionais junto às fábricas e aos locais de trabalho, com o argumento de redução de custos para a União. Isso, somado a fatores conjunturais, propiciou a organização do ensino profissional por meio das Leis Orgânicas do Ensino Industrial, Comercial e Agrícola.

Nos anos de 1940 e 1950, embora tenha ocorrido uma ampla estruturação do ensino e feitas algumas tentativas de se quebrar a dualidade que o caracterizava, esta foi mantida, inclusive no plano legal, pelas finalidades atribuídas ao ensino secundário - a de formar individualidades condutoras - e ao ensino profissional, a de formar trabalhadores. Em 1942, a Reforma Capanema faz o ajuste entre as propostas pedagógicas, então existentes, para a formação de intelectuais e trabalhadores, bem como as mudanças que estavam ocorrendo no mundo do trabalho. Para as elites, são criados os cursos médios de $2^{\circ}$ ciclo, científico e clássico, com três anos de duração, sempre destinados a preparar os estudantes para o ensino superior.

Mesmo o ensino profissional passando à categoria de ensino médio, por meio das Leis Orgânicas dos Ensinos Industrial, Secundário, Comercial, Normal e Agrícola, manteve-se a dualidade do sistema educacional, reafirmada nos objetivos e fundamentos diferentes em cada modalidade de ensino.

10 A formação profissional destinada aos trabalhadores instrumentais passa também a contar com alternativas em nível médio de $2^{\circ}$ ciclo, mas não dava acesso ao ensino superior. As alternativas destinadas à formação de trabaIhadores eram voltadas para as demandas de um processo produtivo no qual as atividades relacionadas aos setores primário, secundário e terciário eram incipientes.

Nesse período também o sistema de ensino profissionalizante passou a ser complementado por um sistema privado de formação para o trabaIho, mantido pela Confederação Nacional da Indústria, que criou o Serviço Nacional de Aprendizagem Industrial (Senai), a partir de 1942, e pelo Serviço Nacional de Aprendizagem Comercial (Senac), mantido pela Confederação Nacional do Comércio, a partir de 1946. Assim, combinam-se a iniciativa pública e a privada para atender a demandas bem definidas decorrentes da divisão social e técnica do trabalho organizado e gerido pelo paradigma taylorista-fordista como resposta ao crescente desenvolvimento industrial que passa a exigir mão de obra qualificada. 
Portanto, historicamente, a organização escolar no Brasil cindiu-se em duas trajetórias escolares específicas, dirigidas a clientelas diferenciadas na sociedade. Em uma delas, o ensino primário seguido por um ensino secundário, complementado por um ensino superior, de caráter profissional, destinado a uma parcela minoritária da população, aquela que atuaria nas posições hierárquicas superiores.

A segunda trajetória possível diz respeito àquela que se constituiu como sendo de preparo e qualificação profissionais diretamente articulados ao trabalho, marcada por finalidade específica: preparar os pobres, marginalizados e desvalidos da sorte, por meio de cursos com duração e intensidade variáveis, desde os cursos de aprendizagem até os cursos técnicos, possibilitando, assim, que aquela clientela atuasse no sistema produtivo por meio de um sistema educacional que disseminasse minimamente, via escola, os códigos formais necessários à sua inserção no trabalho. Esse segundo sistema era paralelo ao sistema regular de ensino, sendo estanque a este, sem uma articulação entre ambos, de forma tal que não se permitia alterações mais substanciais na estrutura social classista como um todo.

Nos anos de 1950, aconteceram algumas tentativas para quebrar, efetivamente, esse caráter dual do sistema de ensino, tanto no sentido de garantir a equivalência entre os dois tipos de ensino, como no de atenuar o caráter específico de cada um. Inicialmente, a equivalência foi assegurada pela possibilidade de os alunos do primeiro ciclo de qualquer ramo terem acesso ao segundo ciclo secundário (Lei n 1.076, de 31 de março de 1950, que assegurava aos estudantes, que concluíssem o curso de primeiro ciclo do ensino comercial, industrial ou agrícola, o direito à matrícula nos cursos clássico e científico), e, depois, pela igualdade de acesso ao vestibular (Lei $n^{\circ}$ 1.821, de 12 de março de 1953, que dispõe sobre o regime de equivalência entre diversos cursos de grau médio para efeito de matrícula no ciclo colegial e nos cursos superiores).

Como os cursos eram muito diferentes, tratou-se de uma formulação para efeitos formais. Era uma legislação conciliatória. De fato, com a Lei n 1.076, de 31 de março de 1950, surgem as primeiras iniciativas do Ministério da Educação, visando tornar os cursos profissionais equivalentes ao curso secundário, mas essa concessão é facultada, apenas, aos concluintes do $1^{\circ}$ ciclo profissional que quisessem ingressar no ciclo colegial secundário. $\bigcirc$ aluno 
Educação profissional, dualidade estrutural e neoprodutivismo

interessado deveria, para isto, completar as disciplinas que faltassem em seu currículo.

A Lei $n^{\circ} 1.821$, de 12 de março de 1953, regulamentada pelo Decreto $n^{\circ} 34.330$, de 21 de outubro de 1953, estende a equivalência ao $2^{\circ}$ ciclo, permitindo-se aos egressos dos cursos técnicos o acesso a qualquer curso superior. Há, entretanto, uma ressalva, conferindo a essa equivalência um caráter limitado: os concluintes dos cursos profissionais só podiam submeter-se aos exames vestibulares desde que aprovados em exames de complementação, ou seja, em exame das matérias dos cursos secundários que não figurassem em seus cursos de origem.

Essas primeiras tentativas de articulação entre as diferentes modalidades de ensino acadêmico e profissionalizante reafirmam o princípio de que o acesso ao nível superior se dá pelo domínio de conteúdos gerais, saberes de classe, os únicos socialmente reconhecidos como válidos para a formação daqueles que desempenharão as funções dirigentes. Portanto, não se reconhece como ciência o saber próprio de um campo específico de trabalho, devendo o candidato ao ensino superior provar competência em línguas, ciências, filosofia e artes (KUENZER, 2000).

Esse processo de organização do sistema educacional brasileiro vai culminar em 1961, com a promulgação da Lei de Diretrizes e Bases da Educação Nacional (LDBEN), de 20 de dezembro de 1961, que se constituiu como a primeira lei global de educação do país. Foi proposta uma concepção orgânica de escola média, simultaneamente global, diversificada e definida por dois pontos básicos: o objetivo de formação comum com anterioridade às especializações, e a equivalência dos seus cursos, considerando o acesso ao ensino superior.

Formalmente, a LDBEN n 4.024, de 20 de dezembro de 1961, destaca a função formativa ao estabelecer no artigo 33 que "[...] a educação de grau médio, em prosseguimento à administrada na escola primária, destina-se à formação do adolescente". Na prática, porém, a função propedêutica do ensino secundário foi reforçada, quando se estabelecia que a $3^{a}$ série colegial teria currículo diversificado, visando ao preparo dos alunos para os cursos superiores, e que poderia ser ministrada em colégios universitários (parágrafo $2^{\circ}$ do art. 46). Em termos de ensino médio, Kuenzer afirma que: 
A história do ensino médio no Brasil é a história do enfrentamento desta tensão, que tem levado, não à síntese, mas à polarização, fazendo da dualidade estrutural a categoria de análise por excelência, para compreensão das propostas que vêm se desenvolvendo a partir dos anos 40 (KUENZER, 2000, p. 10).

Como se observa, nos anos de 1950, o desenvolvimento crescente dos setores secundário e terciário, ocorrido no mundo do trabalho, conduziu ao reconhecimento da legitimidade de outros saberes que não só os de cunho acadêmico. Todavia, a dualidade estrutural continua sendo traduzida pela existência de dois ramos distintos de ensino, para distintas clientelas, voltados para necessidades bem definidas da divisão do trabalho, visando à formação de trabalhadores instrumentais e intelectuais por meio de diferentes projetos pedagógicos.

Portanto, as funções propedêutica e profissionalizante foram bastante acentuadas no período de 1930 a 1961. Ambas respondem às expectativas criadas a partir da modernização do país, com objetivos diferenciados de formação: de um lado, a elite dirigente urbana capaz de dar suporte à política de industrialização; de outro, a qualificação de mão de obra nos limites necessários ao funcionamento do modelo urbano-industrial (CUNHA, 1977). Desse modo, a dualidade administrativa do sistema de ensino encarregava-se da socialização diferenciada entre trabalhadores intelectuais e trabalhadores manuais, o que exclui, por definição, uma formação integral do adolescente.

$\bigcirc$ período entre 1961 e 1981, denominado por modelo urbano-industrial (CUNHA, 1977), culmina com a predominância da função profissionalizante no ensino médio. Até 1964, verifica-se um crescimento das tensões e dos conflitos decorrentes de divergências entre o modelo econômico adotado na década anterior e as aspirações e expectativas de grande parte da população.

De acordo com Saviani (2013), esse constitui o terceiro período da educação brasileira, e a característica marcante será o predomínio da pedagogia nova, desdobrado nas fases: de 1932 a 1947 (equilíbrio entre a pedagogia tradicional e a pedagogia nova; de 1947 a 1961 (predomínio da influência da pedagogia nova), e de 1961 a 1969, crise da pedagogia nova e a articulação da pedagogia tecnicista. 
Educação profissional, dualidade estrutural e neoprodutivismo

Nos meados dos anos de 1960, ocorrem acomodações e reajustes para criar as condições necessárias à fase de crescimento da economia, iniciada por volta de 1967. Essa fase perdurou até 1974, quando se inicia o declínio progressivo das taxas anuais do Produto Interno Bruto (PIB).

$\bigcirc$ modelo de desenvolvimento adotado pelo governo militar, a partir de 1964, buscou a efetiva modernização do país e um modo específico de participar na economia internacional, com consequências importantes nas relações entre educação e trabalho. Surgem grandes empresas e conglomerados econômicos que vão reduzir algumas vias tradicionais de ascensão social: organização de pequenas empresas próprias, ou prestação de serviços como autônomo e, principalmente como profissionais liberais. Por outro lado, a ampliação da estrutura técnica e administrativa do país multiplicou os espaços ocupacionais nas empresas públicas e privadas de níveis mais elevados.

$\bigcirc$ pessoal de nível superior foi o segmento da população economicamente ativa que mais se beneficiou com esse modelo de desenvolvimento. A queda nos salários de base, contraposta às melhores perspectivas existentes para a tecnocracia e ao fechamento das outras vias de ascensão social, provocou grandes pressões das classes médias urbanas, passando a demandar mais 14 vagas de educação em nível superior.

governo atendeu a essas pressões, seja ampliando o número de vagas até esgotar a capacidade ociosa das universidades públicas, seja ampliando as estruturas físicas dos campi universitários, seja diminuindo o rigor para a criação e o reconhecimento de escolas particulares. A corrida ao ensino superior parecia ser estimulada pelas condições do mercado de trabalho que, em fase de expansão, absorvia, praticamente, todos os seus egressos.

Todavia, com o surgimento dos primeiros sinais de distorção e saturação, tornou-se imperioso tomar novas providências. Era necessário conter a pressão sobre a universidade. Contudo, para cumprir esse papel de controlador do fluxo da demanda pelo nível superior, o ensino médio não poderia ser discriminatório, mas esse ajuste já vinha sendo preparado há algum tempo.

De fato, durante o período entre 1969 e 1980, granjeia destaque a pedagogia tecnicista, por exemplo, a partir de um amplo movimento editorial cujas obras publicadas irão fundamentar a opção pelo tecnicismo como orientação para organizar o sistema de ensino. O Valor Econômico da Educação, de Theodore William Schultz (1973), e a coletânea, Desenvolvimento, Trabalho 
e Educação, organizada por Luiz Pereira (1967), são algumas das inúmeras publicações que ocorreram nesse período, ressaltando o foco economicista e tecnicista da educação.

Simultaneamente, sob a liderança de Valnir Chagas, vários ajustes foram feitos na área educacional culminando com a reforma do ensino superior por meio da Lei $n^{\circ}$ 5.540, de 28 de novembro de 1968, que fixa normas de organização e funcionamento do ensino superior e sua articulação com a escola média, e dá outras providências, e da reforma do ensino de $1^{\circ}$ e de $2^{\circ}$ graus, com a Lei $n^{\circ}$ 5.692, de 11 de agosto de 1971, que fixa as Diretrizes e Bases para o Ensino de $1^{\circ}$ e de $2^{\circ}$ Graus e dá outras providências.

Pela primeira vez na história da educação brasileira, ocorre a primazia do ensino profissionalizante em detrimento do ensino secundário. Urge ressaltar que isso aconteceu por pouco tempo, e ficou mais no plano legal do que na realidade das instituições escolares. Com essas medidas, estava pronto o novo arcabouço para a implantação da concepção pedagógica, adotada oficialmente, a tecnicista.

Com base no pressuposto da neutralidade científica e inspirada nos princípios de racionalidade, eficiência e produtividade, a pedagogia tecnicista advoga a reordenação do processo educativo de maneira que o torne objetivo e operacional. De modo semelhante ao que ocorreu no trabalho fabril, pretende-se a objetivação do trabalho pedagógico (SAVIANI, 2013, p. 381 ).

Portanto, coerentemente com esse pressuposto, optou-se, no Congresso Nacional, pela profissionalização universal e obrigatória daquele nível de ensino. Essa decisão revelou-se mais radical do que a proposta pelo Conselho Federal de Educação, mais flexível porque possibilitava a opção por "aprofundamento em determinadas ordens de estudos gerais" ou por uma "habilitação profissional".

Uma análise retrospectiva dessa decisão mostra como uma espécie de reviravolta no processo histórico marcou as tentativas de quebra do dualismo da educação brasileira. Até os anos de 1960, as tentativas de reforma do ensino tomaram, como modelo, o ensino secundário, isto é, ocorriam no sentido de equiparar os cursos técnicos ao secundário, atenuando-se suas peculiaridades e removendo-se, gradualmente, as barreiras entre eles e a universidade. Mas, o que aconteceu em 1971 foi praticamente uma equiparação 
Educação profissional, dualidade estrutural e neoprodutivismo

formal do curso secundário aos cursos técnicos, ou seja, tentou-se mudar o modelo humanístico/científico pelo científico/técnico.

Os antecedentes dessa reviravolta podem ser encontrados já no início dos anos 60. Os fatos mais significativos relativos a essa mudança encontram-se nos trabalhos de Anísio Teixeira, em Mensagem Presidencial, enviada ao Congresso em 1961 e no pronunciamento do Brasil na Conferência sobre Educação e Desenvolvimento Econômico e Social na América Latina, realizada no Chile em 1962 (BRASIL, 1982).

A ideia de unificação do ensino médio estabelecendo uma ligação entre educação e trabalho parece ter surgido com a intensificação do processo de internacionalização da economia do país, nos anos 1956/1960. As grandes empresas multinacionais que, aqui se estabeleceram, introduziram formas mais sofisticadas de organização do trabalho e o uso de tecnologia mais avançada. Esse fato determinou a necessidade de um tipo de socialização específica para os empregados, valorizando o conhecimento técnico-científico em relação às humanidades.

Além disso, os meios intelectuais ligados à educação aceitavam, praticamente, sem restrições, a Teoria do Capital Humano, cujo corolário mais evidente é que mais educação sempre significa melhor salário e mais promoção social. Elaborada por Theodore William Schultz (1973), essa teoria vincula o conceito de capital humano a uma função agregada, de caráter macroeconômico-social entre as nações e as diferenças e desigualdades entre grupos sociais ou entre os indivíduos.

Até 1950, acreditava-se que o desenvolvimento econômico era uma decorrência dos fatores de produção: recursos naturais, capital e trabalho. Estudos, a respeito da temática (SAUL, 2004), revelam a genealogia da Teoria do Capital Humano, anteriormente ao protagonismo de Theodore W. Schultz (1987; 1973; 1973a). A educação passa a ser reconhecida como alternativa para reduzir as disparidades econômicas e para fortalecer as economias regionais.

A educação se encarregaria de preparar os indivíduos para a aplicação de técnicas e ferramentas de gestão, o que reduziria o custo de produção e estimularia o crescimento da economia. Por isso, a partir dos anos de 1950, a educação passa a ser uma atividade lucrativa, um investimento de aplicação do capital, e define a relação trabalho-educação na sociedade capitalista. 
Assim, configurava a Teoria do Capital Humano, que teve origem e base de sustentação numa conjuntura pelo desenvolvimento capitalista marcado pelo crescimento econômico, pelo fortalecimento dos Estados de Bem-Estar Social e pela confiança na conquista do pleno emprego.

Trata-se, portanto, de um conceito que foi construído na fase áurea do modo de regulação fordista de desenvolvimento econômico, o qual explicita, paradoxalmente, os seus profundos limites. A Teoria do Capital Humano concebe o homem não como ser histórico-social, mas como homo oeconomicus. Esse homem, responsável pela maximização da produção e do lucro, é livre nas suas escolhas e no seu consumo. O fator econômico, considerado determinante das ações humanas, mobilizaria o homem nas suas iniciativas e conquistas:

[... é o egoísmo e o interesse do homo oeconomicus quem produzirá a riqueza coletiva. $\bigcirc$ individualismo moderno deste modelo de ser humano está inserido no mercado econômico como um competidor, como um jogador. Para ele é somente seu interesse o que importa e para este modelo de organização social também é somente isto o que importa. $\bigcirc$ homo oeconomicus é o maior responsável por seu fracasso ou por suas glórias, ele é o maior responsável por si mesmo, ele é investidor e empresário de si, ele está sozinho e com todos ao mesmo tempo (NILO, 2010, p. 357).

A educação, na perspectiva dessa teoria, era vista como componente do fator econômico, como um capital individual que teria consequências sobre o capital social. A educação desencadearia a sociedade capitalista a atingir o pleno desenvolvimento e a modernização, eliminando as desigualdades de renda sem, no entanto, abalar as estruturas que produzem essa desigualdade.

Por ser uma teoria elaborada segundo a ótica da classe burguesa, não aborda as contradições sociais construídas na relação capital-trabalho e, assim, mascara a natureza ideológica embutida no vínculo linear entre educação e desenvolvimento $\bigcirc$ conceito de capital humano assume o caráter ideológico inclusive quando tenta esfumaçar a divisão social de classes ao conferir ao indivíduo a responsabilidade e a liberdade de buscar a ascensão social (FRIGOTTO, 1999).

deslocamento de trabalhadores da área de produção imediata para a área de serviços coloca a escola como produtora de indivíduos com 
Educação profissional, dualidade estrutural e neoprodutivismo

requisitos para que possam exercer tais tarefas. Ao mesmo tempo, o grau de escolaridade funciona como parâmetro seletivo a priori, independente da qualificação do posto de trabalho. Por outro lado, o prolongamento da escolaridade funciona como retardatário do ingresso de jovens no mercado de trabalho, buscando-se, ilusoriamente, controlar a relação entre demanda e oferta de empregos. Acreditava-se na possibilidade de generalização da indústria e, em decorrência disso, ocorreria o desenvolvimento social, resultado do pleno emprego e da diminuição das desigualdades. A crise dos anos 70 já evidenciava a precariedade desse pressuposto, quando ocorre uma mudança profunda na base técnica de produção que substitui o fordismo pelo toyotismo:

O modelo fordista apoiava-se na instalação de grandes fábricas operando com tecnologia pesada de base fixa [...]; supunha a estabilidade no emprego. [...] o modelo toyotista apoia-se em tecnologia leve, de base microeletrônica e flexível, e opera com trabalhadores polivalentes que [...] disputem diariamente cada posição conquistada, vestindo a camisa da empresa (SAVIANI, 2013, p. 4291.

Entretanto, nos anos de 1960 e 1970, é forte a crença de que o investimento em capital humano seria capaz de resolver as questões do subdesenvolvimento e das desigualdades internacionais, regionais e individuais. A Teoria do Capital Humano constituiu-se no referencial teórico político e ideológico para a definição de macropolíticas educacionais orientadas pelos organismos internacionais e regionais. No Brasil, durante o período da ditadura militar, as duas reformas - a universitária, de 1968, e a do ensino de $1^{\circ} \mathrm{e}$ $2^{\circ}$ graus, em 1971 - estruturam o sistema de ensino fundamentados nos parâmetros produtivistas, tecnicistas e economicistas, inspirados nessa formulação teórico-ideológica.

Até hoje, os adeptos desta ideologia não respondem à seguinte questão: os países pobres e as populações pobres assim são porque investem pouco em educação ou tem pouca educação porque são pobres? Uma visão que, além de reduzir a educação de um direito social e subjetivo a um serviço mercantil, falseia e obscurece as reais relações sociais que produzem a desigualdade (FRIGOTTO; CIAVATTA, 2016 , p. 30 e 31 ). 
Vários fatores interferem na organização escolar e extrapolam o papel formal da lei. $\bigcirc$ período era de otimismo quando se propôs a Reforma do Ensino de $1^{\circ}$ e $2^{\circ}$ graus em 1971. Em 1972, o próprio presidente do Conselho Federal de Educação dizia que

[...] razões diversas, relacionadas com o desenvolvimento social e com o enriquecimento da Nação Brasileira, nos últimos anos, tornaram grandemente oportunas as diretrizes emanadas da Lei 5692/71, para a renovação do ensino de $2^{\circ}$ grau (BRASIL, 1982, p. 23).

Entretanto, no início da implantação da Lei 5.692, de 11 de agosto de 1971, que fixa as Diretrizes e Bases para o Ensino de $1^{\circ}$ e $2^{\circ}$ Graus e dá outras providências, a ambiguidade de seus termos-chave vai determinar mudanças na sua trajetória. A habilitação específica, inicialmente prevista, diluiu-se em uma educação para o trabalho, numa perspectiva mais geral e abrangente.

As funções formativa, propedêutica e profissionalizante do ensino médio, no Brasil, estão relacionadas à organização do trabalho, em cada época. Vê-se, contudo, que a função formativa, embora pouco explicitada em nível operacional, é a que melhor caracteriza um tipo de ensino médio, na medida em que é responsável pela socialização diferenciada, de acordo com as posições que os indivíduos terão nas hierarquias ocupacionais.

E, nesse sentido pragmático de garantir condições para adaptação dos indivíduos à divisão do trabalho, ela tem sido bastante eficiente. Essa eficiência é, em parte, comprovada pela ineficiência com que têm sido desempenhadas as duas outras funções - propedêutica e profissionalizante - que obrigam o aluno a se valer de dispositivo parassistêmico para ingressar, quer no curso superior, quer no mundo do trabalho. Esses dispositivos se encarregaram de manter, na prática, a dualidade do sistema de ensino, quebrada formalmente pela Lei n 5.692, de 11 de agosto de 1971, que fixa as Diretrizes e Bases para o Ensino de $1^{\circ}$ e de $2^{\circ}$ Graus e dá outras providências.

Com a superação do otimismo gerado pela Teoria do Capital Humano, a sociedade mantém os mesmos referenciais economicistas, mas relega as demandas sociais previstas e a crença no pleno emprego. Nesse novo momento, 
[...] é o indivíduo que terá de exercer sua capacidade de escolha visando a adquirir os meios que the permitam ser competitivo no mercado de trabalho. E o que ele pode esperar das oportunidades escolares já não é o acesso ao emprego, mas apenas a conquista do status de empregabilidade (SAVIANI, 2013, p. 430).

A perspectiva educacional continua sendo economicista e produtivista, bem como importante na sua relação com o mercado. Porém, trata-se agora de um investimento em capital humano individual que habilita para a competição e não mais para o pleno emprego. Os diversos graus de escolaridade, além de retardar o ingresso no mercado de trabalho, amplia as condições de empregabilidade do indivíduo, sem a garantia de que o emprego vai acontecer. "A teoria do capital humano foi, pois, refuncionalizada e é, nessa condição, que ela alimenta a busca de produtividade na educação. Eis por que a concepção produtivista [...] mantém a hegemonia nos anos 1990, assumindo a forma do neoprodutivismo" (SAVIANI, 2013, p. 430).

\section{Educação profissional nos anos de 1990 e início do século XXI: a 20 manutenção da dualidade estrutural e do neoprodutivismo}

Em 1990, é criada a Secretaria Nacional de Educação Tecnológica (SENETE), através do Decreto n 99.244, de 10 de maio de 1990, com a incumbência de traçar as diretrizes e as políticas para o desenvolvimento da educação profissional nos níveis técnico e tecnológico. Posteriormente, a Lei $n^{\circ}$ 8.490, de 19 de novembro de 1992, transforma a SENETE em Secretaria de Educação Média e Tecnológica (SEMTEC), cujo objetivo foi promover o desenvolvimento e a melhoria do ensino médio no país, e, ainda, a implementação da educação profissional, propondo políticas e diretrizes para a área.

No campo do ensino técnico federal, a orientação era a de tornar essa rede de escolas capaz de formar profissionais flexíveis e adequados às mudanças requeridas pelo mundo produtivo sob o ideário neoliberal. Uma das medidas para isso foi a instituição do Núcleo de Qualidade Total do MEC $(N Q T)$, exigindo que todas as escolas técnicas e agrotécnicas instituíssem o seu próprio núcleo de Qualidade Total, de modo a implementar a gestão da qualidade total. Simultaneamente, outras políticas foram elaboradas para inserir 
essas instituições no contexto da educação brasileira e de sua relação com os setores empresariais.

Os esforços que se concentravam na SEMTEC eram para instituir o Sistema Nacional de Educação Tecnológica e para transformar as escolas técnicas e agrotécnicas em Centros Federais de Educação Tecnológica (CEFETs) a curto, médio e longo prazo. A criação desse sistema baseava-se nas políticas de desenvolvimento de países de primeiro mundo, especialmente os europeus, que atribuíam o seu desenvolvimento ao investimento sistematizado na busca e uso intensivo de modernas tecnologias. Identificando o avanço tecnológico desses países e a possibilidade de algo semelhante ocorrer no Brasil, os problemas do desenvolvimento nacional estariam também condicionados às políticas de investimento e de formação de mão-de-obra especializada para operá-las.

É importante ressaltar que a criação do Sistema Nacional de Educação Tecnológica e a transformação das escolas técnicas e agrotécnicas em Centros Federais de Educação Tecnológica (CEFETs), na verdade, constituíam-se em uma proposta fundamentada em uma concepção de educação tecnológica que deveria ser norteadora das ações pedagógicas, administrativas e políticas das Instituições Federais de Educação Tecnológica. Nesse sentido, a conceituação de educação tecnológica foi formulada como sendo "[...] a vertente da educação que se caracteriza por formar profissionais em todos os níveis de ensino e para todos os setores da economia, aptos ao ingresso imediato ao mercado de trabalho" (BRASIL, 1994, p. 9).

Ainda na década de 1990, foi aprovada a Lei n²9.394, de 20 de dezembro de 1996, que, ao estabelecer uma nova estrutura para a educação formal no Brasil, separou o sistema de ensino regular - que compreende a educação básica (educação infantil, ensino fundamental e ensino médio) e o ensino superior - do sistema de educação profissional, subdividido em três níveis: o nível básico (cursos de qualificação profissional), o técnico e o tecnológico. A referida Lei $n^{\circ} 9.394$ e o Decreto $n^{\circ} 2.208$, de 17 de abril de 1997, que regulamenta o $\S 2^{\circ}$ do art. 36 e os artigos 39, 40, 41 e 42 da Lei $n^{\circ}$ 9.394, de 20 de dezembro de 1996, instituíram as bases para a reforma do ensino profissionalizante. Do ponto de vista formal, significou que todas as instituições públicas e privadas de educação profissional tiveram de ajustar-se às diretrizes educacionais estabelecidas pela legislação em vigor à época. 
Educação profissional, dualidade estrutural e neoprodutivismo

Assim, estabelecia o Decreto $n^{\circ} 2.208$, de 17 de abril de 1997, que regulamenta $\circ \S 2^{\circ}$ do art. 36 e os artigos 39 a 42 da Lei 9.394, de 20 de dezembro de 1996:

A Educação Profissional será desenvolvida em articulação com o ensino regular ou em modalidades que contemplem estratégias da educação continuada, podendo ser realizada em escolas do ensino regular, em instituições especializadas ou nos ambientes de trabalho [...] e abrangerá três níveis: o básico, o técnico e o tecnológico (BRASIL, 1997).

A implementação do conjunto de dispositivos legais sobre a educação média e a educação profissional foi financiada por meio de convênios Ministério da Educação, Ministério do Trabalho e do Emprego e Banco Interamericano de Desenvolvimento (MEC/MTE/BID) e pelo Banco Mundial, mediante os programas especiais: Plano Nacional de Educação Profissional (PLANFOR) e Programa de Expansão e Melhoria da Educação Profissional (PROEP).

A legislação complementar à Lei n 9.394, de 20 de dezembro de

22 1996, que estabelece as diretrizes e bases da educação nacional em particular, a Portaria $n^{\circ}$ 646, de 14 de maio de 1997, determinou a separação entre o ensino médio e profissional, gerando sistemas e redes distintas, além de se contrapor à perspectiva de uma especialização profissional como etapa que ocorreria após a conclusão de uma escola básica unitária.

Ocorre, assim, o restabelecimento da dualidade de redes e currículos, quando as pesquisas e reivindicações feitas pelas entidades da sociedade civil acerca das novas demandas de qualificação e profissionalização, em sua maioria, reforçavam a tendência para a incorporação de uma sólida formação escolar básica de nível médio, como condição necessária para uma adequada formação técnico-científica e profissional.

Com a mudança do governo de Fernando Henrique Cardoso para - de Luís Inácio Lula da Silva, algumas alterações nessa política para a educação profissional ocorreram. $\bigcirc$ Decreto $n^{\circ} 2.208$, de 17 de abril de 1997, que regulamenta $\circ \S 2^{\circ}$ do art. 36 e os artigos 39 a 42 da Lei $n^{\circ} 9.394$, de 20 de dezembro de 1996, que estabelece as diretrizes e bases da educação nacional, foi substituído pelo Decreto $n^{\circ} 5.154$, de 23 de julho de 2004, que restabeleceu a possibilidade de oferta do ensino técnico e médio de forma 
integrada, mas manteve as alternativas de essas duas modalidades de ensino ocorrerem, também, de forma separada. Durante esse período, vários ajustes legais foram feitos em relação à Lei n 9.394, de 20 de dezembro de 1996, para atender às reivindicações quanto às modalidades de ensino médio e profissional em suas diferentes áreas.

Outra mudança essencial foi a homologação da Lei nº 11 .892, de 29 de dezembro de 2008, que instituiu a Rede Federal de Educação Profissional e transformou as escolas técnicas, agrotécnicas e os CEFETs em Institutos Federais de Educação, Ciência e Tecnologia, que:

[...] são instituições de educação superior, básica e profissional, pluricurriculares e multicampi, especializados na oferta de educação profissional e tecnológica nas diferentes modalidades de ensino, com base na conjugação de conhecimentos técnicos e tecnológicos com as suas práticas pedagógicas (BRASIL, 2008).

No governo do presidente Michel Temer, uma nova alteração ocorre com a aprovação da Lei $n^{\circ}$ 13.415, de 16 de fevereiro de 2017, que estabelece o ensino médio de tempo integral e prevê a oferta do ensino profissional de nível técnico de forma integrada ao ensino médio, sendo uma opção entre outras. Trata-se de mais um arranjo para conter a expansão do ensino superior, atribuindo ao ensino médio, pelo menos, em uma de suas vertentes, o caráter de terminalidade.

A Lei $n^{\circ} .13413$, de 16 de fevereiro de 2017, explicita, em seu artigo $4^{\circ}$, que se trata de uma substituição do artigo 36 da Lei n 9.394 de 1996, em seus parágrafos $6^{\circ}, 7^{\circ}, 8^{\circ}, 9^{\circ}$ e 10 .

$\S 6^{\circ}$ - A critério dos sistemas de ensino, a oferta de formação com ênfase técnica e profissional considerará: I - a inclusão de vivências práticas de trabalho no setor produtivo ou em ambientes de simulação, estabelecendo parcerias e fazendo uso, quando aplicável, de instrumentos estabelecidos pela legislação sobre aprendizagem profissional; II - a possibilidade de concessão de certificados intermediários de qualificação para o trabalho, quando a formação for estruturada e organizada em etapas com terminalidade; $\S$ 70'- A oferta de formações experimentais relacionadas ao inciso $\checkmark$ do caput, em áreas que não constem do Catálogo Nacional dos Cursos Técnicos, dependerá, para sua continuidade, do reconhecimento pelo respectivo Conselho Estadual de Educação, 
Educação profissional, dualidade estrutural e neoprodutivismo

no prazo de três anos, e da inserção no Catálogo Nacional dos Cursos Técnicos, no prazo de cinco anos, contados da data de oferta inicial da formação; § 8० - A oferta de formação técnica e profissional a que se refere $\circ$ inciso $V$ do caput, realizada na própria instituição ou em parceria com outras instituições, deverá ser aprovada previamente pelo Conselho Estadual de Educação, homologada pelo Secretário Estadual de Educação e certificada pelos sistemas de ensino; § 90 - As instituições de ensino emitirão certificado com validade nacional, que habilitará o concluinte do ensino médio ao prosseguimento dos estudos em nível superior ou em outros cursos ou formações para os quais a conclusão do ensino médio seja etapa obrigatória; $\S 10$ - [...] o ensino medio poderá ser organizado em módulos e adotar o sistema de créditos com terminalidade específica (BRASIL, 2017).

Dessa forma, a Lei n 13.415 , de 16 de fevereiro de 2017, reitera dispositivos legais anteriores, ao propor a antecipação da formação profissional para os alunos que necessitam ir para o mundo do trabalho e suas vicissitudes. Ao se referir que essa formação poderá ocorrer em parceria com outras instituições admite a inexistência de infraestrutura adequada para o cumprimento do dispositivo legal, além de incentivar à iniciativa privada de preencher essa lacuna com o apoio de recursos públicos. Os cursos previstos são aligeirados aos moldes de recentes programas, como, por exemplo, o Programa Nacional de Acesso ao Ensino Técnico e Emprego (Pronatec), que atende aos interesses imediatos das empresas, mas ignoram as necessidades que surgem com a complexidade do mundo do trabalho ao implantar as tecnologias avançadas, capazes de competir no mercado internacional. Essas tecnologias exigem educação geral de qualidade e formação profissional diferenciada.

Em relação ao Ensino Médio, como comentado no início deste artigo, a organização das áreas de conhecimento pressupõe o encaminhamento para as áreas de humanidades e ciências, retomando o que a Reforma Capanema denominou, na década de 1940, quanto ao ensino médio de clássico e científico.

Mais uma vez, a legislação nega o direito de uma formação integral para os brasileiros, antecipa as opções para a continuidade de estudos e/ou para a formação profissional, reforçando a tradição da dualidade do sistema educacional. Isso ocorre num contexto de revisão das leis trabalhistas que acentuam a perda de direitos adquiridos em um momento crítico da economia, com 
milhões de brasileiros desempregados. Mesmo fazendo parte da educação básica, o ensino médio que deveria culminar com um processo de formação cidadã - o que seria um avanço - posterga esse direito com a promulgação da Lei $n^{\circ} 13.315$, de 16 de fevereiro de 2017.

Para Saviani (2013), nesse último período, o quarto da educação brasileira (1969-2001) tem como marco a Revolução de 1964, e nele ocorre o confronto entre a concepção produtivista de educação e as pedagogias críticas. Nesse período, Saviani (2013) identifica as seguintes fases: de 19691980, há o predomínio da pedagogia tecnicista, manifestações da concepção analítica de filosofia da educação e desenvolvimento da visão crítico-reprodutivista; de 1980 a 1991 ocorrem alguns ensaios contra-hegemônicos: pedagogia da "educação popular", pedagogia da prática, pedagogia crítico-social dos conteúdos e pedagogia histórico-crítica; de 1991 a 2001, há o predomínio do neoprodutivismo e suas variantes: neo-escolanovismo, neoconstrutivismo e neotecnicismo. Para efeito de conclusão da pesquisa realizada, Saviani (2013) coloca 2001 como limite final desse período.

Todavia, acontecimentos posteriores indicam a continuidade do neoprodutivismo, enquanto referencial teórico oficial na organização dos sistemas de ensino. Observa-se, também, a presença de propostas contra-hegemônicas na realidade atual da educação brasileira, em particular no contexto da pós-graduação, porém com um alcance bem reduzido em termos da realidade educacional, desde que se considera o pequeno percentual de brasileiros que chegam a esse nível de escolaridade.

Realmente, há vários programas com linha de pesquisas orientadas numa perspectiva do materialismo dialético com algumas configurações específicas: a Psicologia Histórico-Cultural, cujo protagonista é Lev Semionovich Vygotsky, que tem, como proposta pedagógica, o Ensino Desenvolvimental; a Pedagogia Crítico-social dos Conteúdos, liderada por José Carlos Libâneo; e a Pedagogia Histórico-Crítica sob a liderança de Dermeval Saviani. Como política oficial, o Estado do Paraná é o único da federação brasileira que adota essa perspectiva teórica como diretriz para a organização do sistema estadual de ensino,

Por isso, atualmente, permanece o desafio de repensar a educação profissional brasileira, de identificar e analisar as concepções que fazem parte desse universo sócio-político-ideológico integrado pelos diferentes protagonistas 
da educação profissional, ou seja, o Estado, as entidades sindicais, as organizações não governamentais, as entidades empresariais e os pesquisadores.

Urge refletir sobre o neoprodutivismo através de suas variantes (neo-escolanovismo, neoconstrutivismo e neotecnicismo), que ainda predomina como referencial teórico das propostas educacionais oficiais, bem como também refletir sobre a possibilidade de se buscar outros referenciais como aquele trabalhado na ótica do materialismo dialético. Como a realidade educacional brasileira está permeada por diferentes orientações teóricas, fica aqui a observação de Saviani (2013, p. 383): "Do ponto de vista pedagógico, conclui-se que, se para a pedagogia tradicional a questão central é aprender, e para a pedagogia nova, aprender a aprender, para a pedagogia tecnicista o que importa é aprender a fazer".

Portanto, a realidade educacional brasileira constitui-se num grande mosaico, em que estão presentes diferentes referenciais teóricos, com padrões bastante diferenciados em termos de qualidade de ensino, dependendo da clientela a que se destina. A dualidade estrutural continua configurando trajetórias e finalidades diferentes para classes sociais distintas.

\section{Considerações Finais}

A relativa ampliação de direitos conquistados pelos trabalhadores durantA abordagem histórica - em particular desde a Primeira República 11889 1930) até os dias atuais, sobre o ensino profissional e o seu embate junto ao ensino médio - deixa transparecer a dualidade estrutural entre ambos, bem como o ajuste do ensino profissional às necessidades do mundo produtivo. Inicialmente, no Brasil Colônia, a educação era praticamente inexistente, com o registro de algumas realizações dos jesuítas objetivando catequizar os escravos e os povos aqui encontrados, desconsiderando a sua cultura e, ao mesmo tempo, propiciando alguma formação aos filhos dos colonos mais ricos.

O processo de colonização e o posterior uso da mão de obra escrava vão marcar, de forma indelével, a cultura brasileira com reflexos constantes nas propostas de formação profissional sempre vistas com a pecha escravocrata. Do início da República até os dias atuais, a constante dualidade estrutural revela as diferenças entre as classes sociais, determinando trajetórias diferentes para os que vão assumir os cargos de direção em diferentes instâncias, em 
relação ao demais trabalhadores, dependendo do posicionamento que cada classe social terá no sistema produtivo.

Nos meados do século XX, com a emergência da Teoria do Capital Humano, atribuiu-se especial ênfase à função econômica da educação, conferindo aos modelos educacionais um formato produtivista e tecnicista. A partir de 1970, com a crise do capitalismo e o esgotamento da Teoria do Capital Humano, sem desconsiderar a ótica economicista, surge o conceito de empregabilidade que enfatiza a dimensão do desenvolvimento humano individual e retira o foco das demandas coletivas que eram consideradas como capazes de desencadear o pleno emprego e o desenvolvimento social.

Com a empregabilidade, a questão do sucesso profissional passa a ser vista, predominantemente, relacionada ao âmbito das competências e habilidades pessoais. $\bigcirc$ que altera é a certeza de que o desenvolvimento econômico ocorre mesmo com a redução drástica de recursos humanos. A inserção no mercado de trabalho, a partir daquele momento, passa a depender das competências individuais. Trata-se, como se observa, de uma continuidade, a confirmar o triunfo de uma escola produtivista/tecnicista em vigência desde o século XIX, sob a tutela da II Revolução Industrial, aos dias atuais. Nesse âmbito, a escola oscilaria para o lado da ciência e da técnica. Pleiteia-se, projetivamente, que a escola deva servir à prosperidade, ao progresso, ao desenvolvimento. E a estes, a criança como sujeito configura-se enquanto conformada aos mesmos.

As demandas coletivas associadas à ideia do pleno emprego, prevista na Teoria do Capital Humano, eram uma falácia. $O$ desemprego já existente aumenta e torna-se um fenômeno estrutural, e milhares de seres humanos ficam à margem dos ganhos do capital. A Teoria do Capital Humano continua direcionando a concepção produtivista da educação brasileira, agora reconceitualizada como neoprodutivismo para atender a um contexto socioeconômico baseado na exclusão, uma vez que não há lugar para todos na atual ordem econômica. Com o avanço da automação no processo produtivo, ocorre também, o aumento da dispensa de mão de obra.

Nesse contexto, consolida-se a pedagogia da exclusão que incentiva a realização incessante de cursos para tornar os indivíduos empregáveis e, assim, escaparem da condição de excluídos. E, nessa condição, mesmo com os mais diferentes títulos, ao permanecerem fora do mundo do trabalho, a 
responsabilidade é de cada um. Esse é um problema social enorme, e é fato que a busca incessante por mais qualificação não garante uma vaga no mercado. Mesmo assim, o sistema de ensino profissional busca estabelecer essa relação entre qualificação profissional e emprego. E o conjunto dos professores também não consegue formular uma proposta educacional mais humana e comprometida com o desenvolvimento integral dos jovens brasileiros.

desafio que se coloca é o de reverter essa situação buscando o resgate da dignidade de milhares de seres humanos condenados à marginalidade das conquistas que a humanidade conseguiu com o capital e com o desenvolvimento científico e tecnológico. Será possível colocar essas conquistas em prol do desenvolvimento humano e social, transformando a realidade social, política, econômica, cultural e educacional de modo mais lúcido e efetivo?

\section{Referências}

BRASIL. Collecção das Leis do Brazil de 1809. Rio de Janeiro: Imprensa Nacional, 1891. Disponível em: https://upload.wikimedia.org/wikipedia/commons/f/fb/ 28 Cole\%C3\%A7\%C3\%A3o_das_leis_do_Brasil_de_1809_Parte_1.pdf. Acesso em: 11 jan. 2019.

BRASIL. Constituição da República dos Estados Unidos do Brasil, de 24 de fevereiro de 1891. Disponível em: <http://www.planalto.gov.br/ccivil_O3/constituicao/constituicao91.htm>. Acesso em: 8 fev. 2018.

Decreto $\mathrm{n}^{\circ}$ 1.606, de 29 de dezembro de 1906. Crea uma Secretaria de Estado com a denominação de Ministerio dos Negocios da Agricultura, Industria e Commercio. Disponível em: <http://www2.camara.leg.br/legin/fed/decret/1900-1909/decreto1606-29-dezembro-1906-582057-norma-pl.html>. Acesso em: 8 fev. 2018.

Lei ${ }^{\circ}$ 1.076, de 31 de março de 1950. Assegura aos estudantes que concluírem curso de primeiro ciclo do ensino comercial, industrial ou agrícola, o direito à matrícula nos cursos clássico e científico e dá outras providências. 1950. Disponível em: <http://www2. camara.leg.br/legin/fed/lei/1950-1959/lei-1076-3 1 -marco-1950-363480-publicacaooriginal-1-pl.html>. Acesso: 8 fev. 2018.

Decreto-Lei ${ }^{\circ}$ 7.566, de 23 de setembro de 1909. Cria nas capitaes dos Estados da Escolas de Aprendizes Artífices, para o ensino profissional primário e gratuito. 1909. Disponível em: <http://portal.mec.gov.br/setec/arquivos/pdf3/decreto_7566_1909. pdf>. Acesso em: 8 fev. 2018. 
Decreto $\mathrm{n}^{\circ}$ 12.893, de 28 de fevereiro de 1918. Autoriza o Ministro da Agricultura a crear patronatos agricolas, para educação de menores desvalidos, nos postos zootechnicos, fazendas-modelo de criação, nucleoscoloniaes e outros estabelecimentos do Ministerio. 1918. Disponível em: <http://www2.camara.leg.br/legin/fed/decret/1910-1919/ decreto-1 2893-28-fevereiro-1918-507076-norma-pe.htmk. Acesso em: 8 fev. 2018.

Constituição dos Estados Unidos do Brasil, de 10 de novembro de 1937. Disponível em: <http://www. planalto.gov

Decreto-Lei $\mathbf{n}^{\circ} \mathbf{9 8 2}$, de $\mathbf{2 3}$ de dezembro de 1938. Cria novos órgãos no Ministério da Agricultura, reagrupa e reconstitui alguns dos já existentes e dá outras providências. 1938. Disponível em: <http://www2.camara.leg.br/legin/fed/declei/1930-1939/ decreto-lei-982-23-dezembro-1938-350702-publicacaooriginal-7-pe.html>. Acesso em: 8 fev. 2018.

. Lei ${ }^{\circ}$ 16.826, de 13 de outubro de 1944. Aprova o Regimento da Superintendência do Ensino Agrícola e Veterinário, do Ministério da Agricultura. 1944. Disponível em: <http:// www2.camara.leg.br/legin/fed/decret/1940-1949/decreto-1 6826-13-outubro-1944-4611 101 -publicacaooriginal-1-pe.html>. Acesso em: 8 fev. 2018.

Lei $\mathbf{n}^{\circ} \mathbf{1 . 8 2 1}$, de 12 de março de 1953. Dispõe sobre o regime de equivalência entre diversos cursos de grau médio para efeito de matrícula no ciclo colegial e nos cursos superiores. 1953. Disponível em: <htp://www2.camara.leg.br/legin/fed/lei/1950-1959/ lei-1821-12-marco-1953-366631-normaatualizada-pl.html>. Acesso em: 8 fev. 2018.

Decreto $\mathbf{n}^{\circ}$ 34.330, de 21 de outubro de 1953. Regulamenta a Lei $n^{\circ} 1.821$, de 12 de março de 1953. Disponível em: <http://www2.camara.leg.br/legin/fed/ decret/1950-1959/decreto-34330-21-outubro-1953-326 101 -republicacao-60374-pe. html>. Acesso em: 8 fev. 2018.

Lei ${ }^{\circ}$ 4.024, de 20 de dezembro de 1961. Fixa as Diretrizes e Bases da Educação Nacional. Rio de Janeiro: Livraria Agir, 1968. (Coleção AEC).

Lei ${ }^{\circ}$ 5.540, de 28 de novembro de 1968. Fixa normas de organização e funcionamento do ensino superior e sua articulação com a escola média, e dá outras providências. Disponível em: https://presrepublica.jusbrasil.com.br/legislacao/109783/lei-5540-68. Acesso em: 04 jan. 2019

Lei $\mathbf{n}^{\circ}$ 5.692, de 11 de agosto de 1971. Fixa as Diretrizes e Bases para o Ensino de $1^{\circ}$ e de $2^{\circ}$ Graus e dá outras providências. 1971. Disponível em: <http://www2. camara.leg.br/legin/fed/lei/1970-1979/lei-5692-1 1-agosto-1971-357752-publicacaooriginal-1-pl.html>. Acesso em: 8 fev. 2018. 
Educação profissional, dualidade estrutural e neoprodutivismo

Decreto $\mathbf{n}^{\circ}$ 99.244, de 19 de maio de 1990. Dispõe sobre a reorganização e o funcionamento dos órgãos da Presidência da República e dos Ministérios, e dá outras providências. 1990. Disponível em: http://www2.camara.leg.br/legin/fed/decret/1990/ decreto-99244-10-maio-1990-334848-publicacaooriginal-1-pe.html. Acesso em: 08 fev. 2018

Lei $\mathbf{n}^{\circ} \mathbf{8 . 4 9 0}$, de 10 de novembro de 1992. Dispõe sobre a organização da Presidência da República e dos Ministérios e dá outras providências. 1992. Disponível em: <http://www. planalto.gov.br/ccivil_03/LEIS/L8490.htm>. Acesso em: 8 fev. 2018.

Ministério da Educação. Educação Média e Tecnológica. Fundamentos, diretrizes e linhas de Ação. Brasília: SEMTEC - Departamento de Políticas Educacionais. 1994. 1994.

Ministério da Educação. Educação Tecnológica: legislação básica. Brasília, SEMTEC,

Lei $\mathbf{n}^{\circ}$ 9.394, de 20 de dezembro de 1996. Estabelece as diretrizes e bases da educação nacional (LDB). Diário Oficial [da] União, Poder Executivo, Brasília, DF, 23 dez. 1996. Seção 1. p. 27833

Decreto $\mathbf{n}^{\circ}$ 2. 208, de 17 de abril de 1997. Regulamenta $\circ \S 2^{\circ}$ do art. 36 e os artigos 39 a 42 da Lei 9.394, de 20 de dezembro de 1996, que estabelece as diretrizes e 30 bases da educação nacional. 1997. Disponível em: <http://portal.mec.gov>. Acesso em: 20 jan. 2018.

Portaria $\mathrm{n}^{\circ}$ 646, de 14 de maio de 1997. Regulamenta a implantação do disposto nos artigos 39 a 42 da Lei Federal n 9.394/96 e no Decreto Federal n².208/97 e dá outras providências (trata da rede federal de educação tecnológica). 1997. Disponível em: <http://portal.mec.gov.br/setec/arquivos/pdf/PMEC646_97.pdf>. Acesso em: 8 fev. 2018.

Decreto $\mathbf{n}^{\circ}$ 5.154, de 23 de julho de 2004. Regulamenta $\circ \S 2^{\circ}$ do art. 36 e os arts. 39 a 41 da Lei no 9.394 de 20 de dezembro de 1996, que estabelece as diretrizes e bases da educação nacional, e dá outras providências. 2004. Disponível em: <http:// www. planalto.gov.br>. Acesso em: 20 jan. 2018.

Lei $\mathbf{n}^{\circ}$ 11.892, de 29 de dezembro de 2008. Institui a Rede Federal de Educação Profissional, Científica e Tecnológica, cria os Institutos Federais de Educação, Ciência e Tecnologia, e dá outras providências. 2008. Disponível em: <http://www.planalto.gov.br/ ccivil_03/_ato2007-2010/2008/lei/11 1892.htm>. Acesso em 8 fev. 2018.

Lei $n^{\circ}$ 13.415, de 16 de fevereiro de 2017. Institui a Política de Fomento à Implementação de Escolas de Ensino Médio em Tempo Integral. 2017. Disponível em: 
<http://www.planalto.gov.br/ccivil_03/_ato2015-2018/2017/lei//13415.htm>. Acesso em: 5 mar. 2018.

A profissionalização do ensino na Lei $\mathbf{n}^{\circ}$ 5692/71. Brasília: Inep, 1982. (Trabalho apresentado pelo INEP à Reunião conjunta do Conselho Federal de Educação com os Conselhos Estaduais de Educação).

CUNHA, Luiz Antônio. Política educacional no Brasil: a profissionalização no Ensino Médio. 2. ed. Rio de Janeiro: Eldorado, 1977.

CURY, Carlos Roberto Jamil. Políticas atuais para o ensino médio e a educação profissional de nível técnico: problemas e perspectivas. In: ZIBAS, Dagmar; AGUIAR, Márcia; BUENO, Maria (Org.). O ensino médio e a reforma da educação básica. Brasília: Plano Editora, 2002.

FERREIRA, Eurípedes Ronaldo Ananias. O ensino técnico profissional agrícola de nível médio: o sistema escola fazenda da Coordenação Nacional do Ensino Agropecuário. 2002. Tese (Doutorado em Educação Escolar), Universidade Estadual Paulista, Araraquara, 2002.

FRIGOTTO, Gaudêncio (Org.). Educação e crise do trabalho: perspectivas de final de século. Petrópolis, RJ: Vozes, 1999.

FRIGOTTO, Gaudêncio; CIAVATTA, Maria (Org.). Teoria e educação no labirinto do capital. 4. ed. São Paulo: Expressão Popular, 2016.

KUENZER, Acácia Zeneida. Ensino médio e profissional: as políticas do Estado neoliberal. 2. ed. São Paulo: Cortez, 2000.

MACHADO, Lucília Regina de Souza. Educação e divisão social do trabalho: contribuição para o estudo do ensino técnico industrial brasileiro. 2. ed. São Paulo: Autores Associados/ Cortez, 1989.

$\mathrm{NILO}$, Tiago. Alguns apontamentos sobre a governamentabilidade liberal e/ou neoliberal a partir de Michel Foucault. Kínesis, Marília, v. 2, n. 3, p. 345-358, abr. 2010. Disponível em: <http://www.marilia.unesp.br/Home/RevistasEletronicas/Kinesis/25_TiagoNilo. pdf>. Acesso em: 8 fev. 2018.

RIBEIRO, Maria Luisa Santos. História da educação brasileira: a Organização Escolar. São Paulo: Cortez \& Moraes, 1978.

ROMANELLI, Otaíza de Oliveira. História da educação no Brasil: 1930/1973. Petrópolis: Vozes, 1995.

SAUL, Renato. As raízes renegadas da teoria do capital humano. Sociologias, Porto Alegre, v. 6, n. 12, p. 230-273, jul./dez. 2004. 
SAVIANI, Dermeval. História das ideias pedagógicas no Brasil. 4. ed. Campinas: Autores Associados, 2013.

neoprodutivismo e suas variantes: neoescolanovismo, neoconstrutivismo, neotecnicismo (1991-2001). In: SAVIANI, Dermeval. História das ideias pedagógicas no Brasil. 4. ed. Campinas: Autores Associados, 2013.

SCHULTZ, Theodore William. Investindo no povo: o significado econômico da qualidade da população. São Paulo: Forense Universitária, 1987.

O valor econômico da educação. Tradução P. S. Werneck. 2. ed. Rio de Janeiro: Zahar Editores, 1973.

O capital humano: investimentos em educação e pesquisa. Rio de Janeiro: Zahar Editores, 1973a.

Ms. Elisabete Ferreira Borges Técnica em Assuntos Educacionais no Instituto Federal de Educação, Ciência e Tecnologia do Triângulo Mineiro (Uberaba - Minas Gerais, Brasil)

ORCID ID: http: / / orcid.org/0000-0002-9157-3722

E-mail: elisabete_borges@uol.com.br

Prof. Dr. José Carlos Souza Araújo Universidade de Uberaba (Minas Gerais, Brasil) Programa de Pós-Graduação em Educação Grupo de Pesquisa: Núcleo de Estudos e Pesquisas em História e Historiografia da Educação ORCID ID: http: / / orcid.org/0000-0002-7972-8875 E-mail: jcaraujo.ufu@gmail.com Recebido 22 nov. 2018 Aceito 27 dez. 2018 